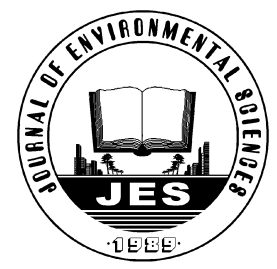

\title{
Homogeneous and heterogeneous reactions of anthracene with selected atmospheric oxidants
}

\author{
Yang Zhang ${ }^{1,2, *}$, Jinian Shu ${ }^{1}$, Yuanxun Zhang ${ }^{2}$, Bo Yang ${ }^{1}$ \\ 1. Research Center for Eco-Environmental Sciences, Chinese Academy of Sciences, Beijing 100085, China \\ 2. University of Chinese Academy of Sciences, Beijing 100049, China
}

Received 28 November 2012; revised 24 December 2012; accepted 27 February 2013

\begin{abstract}
The reactions of gas-phase anthracene and suspended anthracene particles with $\mathrm{O}_{3}$ and $\mathrm{O}_{3}-\mathrm{NO}$ were conducted in a 200-L reaction chamber, respectively. The secondary organic aerosol (SOA) formations from gas-phase reactions of anthracene with $\mathrm{O}_{3}$ and $\mathrm{O}_{3}-\mathrm{NO}$ were observed. Meanwhile, the size distributions and mass concentrations of SOA were monitored with a scanning mobility particle sizer (SMPS) during the formation processes. The rapid exponential growths of SOA reveal that the atmospheric lifetimes of gas-phase anthracene towards $\mathrm{O}_{3}$ and $\mathrm{O}_{3}$-NO are less than 20.5 and $4.34 \mathrm{hr}$, respectively. The particulate oxidation products from homogeneous and heterogeneous reactions were analyzed with a vacuum ultraviolet photoionization aerosol time-of-flight mass spectrometer (VUVATOFMS). Gas chromatograph/mass spectrometer (GC/MS) analyses of oxidation products of anthracene were carried out for assigning the time-of-flight (TOF) mass spectra of products from homogeneous and heterogeneous reactions. Anthrone, anthraquinone, 9,10dihydroxyanthracene, and 1,9,10-trihydroxyanthracene were the ozonation products of anthracene, while anthrone, anthraquinone, 9-nitroanthracene, and 1,8-dihydroxyanthraquinone were the main products of anthracene with $\mathrm{O}_{3}$-NO.
\end{abstract}

Key words: anthracene; ozonation; secondary organic aerosol; heterogeneous reaction; aerosol mass spectrometer DOI: $10.1016 /$ S1001-0742(12)60233-2

\section{Introduction}

Polycyclic aromatic compounds (PAHs), which mainly derived from incomplete combustion of organic compounds and fossil fuels (Emmenegger et al., 2005; Finlayson-Pitts and Pitts, 2000; Herner et al., 2001; Kou et al., 2008), are ubiquitous environmental contaminants. Once emitted into the atmosphere, these compounds would partition between the gas phase and atmospheric aerosol particles. Naphthalene ( 2 rings) and semivolatile (3-4 rings) PAHs can be found both in gas- and particle-phase due to their low vapor pressure, whereas PAHs bearing five fused rings or more are predominately in particulate matter (Calvert et al., 2000; Nikolaou et al., 1984; Sitaras et al., 2004; Vasilakos et al., 2007; Vione et al., 2004). These pollutants receive considerable research attentions because they have mutagenic and carcinogenic effects on human health (Durant et al., 1996; Pitts et al., 1978).

PAHs can react with atmospheric oxidants such as $\mathrm{O}_{3}, \mathrm{NO} x\left(\mathrm{NO}+\mathrm{NO}_{2}\right), \mathrm{OH}$ radicals, and $\mathrm{NO}_{3}$ radicals, often yielding degradation products such as quinones,

\footnotetext{
* Corresponding author. E-mail: zhangyang@ucas.ac.cn
}

ketones, aldehydes, and nitro-PAHs etc., which may be more carcinogenic and mutagenic than the parent $\mathrm{PAH}$ (Atkinson and Arey, 1994; Durant et al., 1996; Herner et al., 2001; Pitts et al., 1978; Umbuzeiro et al., 2008). In addition, secondary organic aerosol (SOA) resulted from the homogeneous reactions between low weight PAHs and atmospheric oxidants aggravates directly (human health, visibility, light scattering, and light absorption) and indirectly (cloud and haze formation) the particle pollution (Chuong et al., 2004; Ervens and Kreidenweis, 2007; Kanakidou et al., 2005). Thus PAHs reactions with atmospheric oxidants have been reported in many literatures. Past studies on atmospheric PAH degradation have focused on two areas: kinetic and reaction rate studies on atmospheric oxidants with PAHs in gas phase or adsorbed on different substrates; and studies on product identification, product yield and reaction mechanism. Early studies on such reactions mainly paid close attention to the gas phase PAHs with less than three benzenoid rings. Most of these researches were designed to obtain the reaction rates and yields of SOA (Atkinson and Arey, 1994, 2007; Atkinson et al., 1990; Atkinson and Aschmann, 1988; Helmig and Harger, 1994; Wang et al., 2007). In the last decade, the 
reactions of gas phase oxidants with PAHs dissolved in organic solvents or coated on various kinds of nucleus were studied intensively. Lots of investigations on the product identifications of the gas-liquid and gas-solid reactions of atmospheric oxidants with PAHs have been carried out (Ma et al., 2011; Miet et al., 2009a, 2009b, 2009c; Mmereki and Donaldson, 2003; Mmereki et al., 2004; Nájera et al., 2011; Pöschl et al., 2001; Perraudin et al., 2007a, 2007b; Raja and Valsaraj, 2006; Yao et al., 1998b; Zhang et al., 2010, 2011).

Three-ring member anthracene (An) exists both in gas phase and particle matter in ambient air (Sitaras et al., 2004). A number of recent experimental studies have utilized An as a PAH proxy representative of the wider class of aromatic species because it is present in polluted atmospheres at typical concentrations of approximately $6 \mathrm{ng} / \mathrm{m}^{3}$ (Finlayson-Pitts and Pitts, 2000). Early studies of the liquid-phase reaction of anthracene solution with dissolved ozone by Bailey identified anthraquinone and phthalic acid as the main reaction products (Bailey, 1982). Recently, the reported research reveals that heterogeneous reactions may be the dominant loss process of atmospheric PAHs (Miet et al., 2009a, 2009b; Pöschl et al., 2001; Perraudin et al., 2007a, 2007b). More recent studies have concentrated on characterizing the ozonolysis mechanism and product yields for anthracene on a variety of different substrates such as aqueous and organic interfaces (Kahan et al., 2006; Mmereki and Donaldson, 2003; Mmereki et al., 2004), film surfaces (Kwamena et al., 2006; Nájera et al., 2011), and on both organic and inorganic aerosol surfaces (Gloaguen et al., 2006; Kwamena et al., 2006, 2007; Ma et al., 2010; Perraudin et al., 2007b). There are, however, significant discrepancies in both the experimentally reported reaction products and the reported rates of reaction for ozonolysis. Furthermore, the SOA formation from homogeneous reactions of anthracene is not well documented though anthracene, mainly existing in gas phase in the atmosphere (Sitaras et al., 2004), is the potential precursor for SOA formation. Besides, reactions of anthracene with $\mathrm{NO} x$ in the presence of $\mathrm{O}_{3}$ may be of significance to the atmospheric chemistry in highly photochemical smog pollution cities. However, there is only limited reliable and consistent data for the reactions between anthracene and nitrogen oxides such as $\mathrm{NO}_{2}$ and $\mathrm{NO}_{3}$ radicals (Ma et al., 2011; Zhang et al., 2011).

In this article, the homogeneous and heterogeneous reactions of anthracene with $\mathrm{O}_{3}$ and $\mathrm{O}_{3}-\mathrm{NO}$ were conducted in a reaction chamber. The SOA formations from the reactions of gas-phase anthracene with $\mathrm{O}_{3}$ and $\mathrm{O}_{3}$-NO were observed with a scanning mobility particle sizer. The timeof-flight mass spectra of particulate reaction products from the reactions of gas and aerosol phase anthracene with $\mathrm{O}_{3}$ and $\mathrm{O}_{3}$-NO were obtained with the vacuum ultraviolet photoionization time-of-flight aerosol mass spectrometer (VUV-ATOFMS). The main reaction products were iden- tified and assigned via GC/MS analyses.

\section{Experimental section}

The initial concentrations of gas-phase oxidants are as follows: for homogeneous at $\mathrm{O}_{3}$ of $5.1 \mathrm{ppmV}, \mathrm{O}_{3}+\mathrm{NO}$ of $4.2 \mathrm{ppmV}+0.5 \mathrm{ppmV}$; for heterogeneous at $\mathrm{O}_{3}$ of $15.3 \mathrm{ppmV}, \mathrm{O}_{3}+\mathrm{NO}$ of $28.6 \mathrm{ppmV}+6.2 \mathrm{ppmV}$. The experimental setup has been described in detail elsewhere (Zhang et al., 2010). It consists of a chamber, an aerosol generator, and analytic instruments.

\subsection{Chamber}

The chamber comprises a thin-walled open head stainless steel drum $(50 \mathrm{~cm}$ (outer diameter) $\times 60 \mathrm{~cm}$ (height) and a thin Tedlar polyvinyl fluoride (PVF) film bag (50 $\mathrm{cm}$ (diameter) $\times 50 \mathrm{~cm}$ (length)). Flexible PVF bag was used to keep one atmospheric pressure in the chamber. The volume of the chamber is about $200 \mathrm{~L}$ when PVF bag is fully filled. A muffle fan was set at the bottom of the chamber to ensure that the reactants could be mixed rapidly and sufficiently. The chamber was flushed with filtered air before each experiment. The relative humidity in the chamber was less than $3 \%$ during experiments.

\subsection{Aerosol generator}

The aerosol generator is an electric tube furnace equipped with two tandem quartz tubes $(50 \mathrm{~cm}$ (length) $\times 3 \mathrm{~cm}$ (inner diameter)), each of which was fitted out an independent temperature controller. Suspended anthracene particles were generated through the homogeneous nucleation. Azelaic acid was placed in the first tube $(413 \pm 1 \mathrm{~K})$, while anthracene in the second $(385 \pm 2 \mathrm{~K})$. A $\mathrm{N}_{2}$ stream with a volumetric flow rate of $0.6 \mathrm{~L} / \mathrm{min}$ flowed through the first tube, bringing the nuclei into the second tube. Azelaic acid nuclei were thereby coated by anthracene in the second tube. The thickness of coating, controlled by the temperature of quartz tube and flow rate of $\mathrm{N}_{2}$, was about $25 \mathrm{~nm}$.

\subsection{Instruments}

The concentration of gas-phase anthracene was measured by a gas chromatograph with a flame ionization detection (GC-FID, East \& West Analytical Instruments, Inc. China). A filter containing resin (200 g Amberlite XAD2 (Sigmae Aldrich)) collected gas-phase anthracene and then the resin was extracted ultrasonically. The filtered and concentrated extracts were measured with GC-FID. The chemical compositions of particles in the chamber were analyzed in real-time with the home-built VUV-ATOFMS (Shu et al., 2008). The size and concentration of particles were monitored with a scanning mobility particle sizer (SMPS), which is composed of a differential mobility analyzer (DMA, TSI 3081) and a condensation particle counter (CPC, TSI 3010). The mass concentrations of or- 
ganic particles were calculated from the size distributions and particle density (assumed to be $1.2 \mathrm{~g} / \mathrm{cm}^{3}$ ). Ozone was produced by an ozone generator (Shandong NIPPON, China) and its concentration in chamber was measured with an ozone monitor (Model 202, 2B Technologies, Inc.).

The reaction products were identified with an Agilent $6890 \mathrm{GC} / \mathrm{MS}$, equipped with a $30 \mathrm{~m} \times 0.25 \mathrm{~mm} \times 0.25$ $\mu \mathrm{m}$ HP-5 capillary and a HP-5973 quadrupole mass filter with $70 \mathrm{eV}$ electron impact (EI) ionizer. Sample collection and preparation was the same as description in measuring gas-phase anthracene vapor. One microlitre of sample is introduced via splitless mode. The PTV was held at $270^{\circ} \mathrm{C}$. The initial oven temperature was $90^{\circ} \mathrm{C}$ for $2 \mathrm{~min}$, then ramped at $5^{\circ} \mathrm{C} / \mathrm{min}$ to $300^{\circ} \mathrm{C}$ and held for $5 \mathrm{~min}$. The carrier gas is helium at a constant flow rate of 1.0 $\mathrm{mL} / \mathrm{min}$. The interface temperature was kept at $280^{\circ} \mathrm{C}$. The reaction products were analyzed by GC/MS in the total ion chromatogram (TIC) mode and identified by comparing the EI mass spectra of the products with those from the National Institute of Standards and Technology (NIST) Mass Spectral Library 2005. Anthracene and its reaction products detected and identified with GC/MS were listed in Table 1.

\subsection{Chemicals}

Anthracene (Alfa, 97\%) and azelaic acid (99\%, Special Chemical Reagent Development Center in North Region of China) were used in the experiment. Oxygen (99.99\%), nitrogen (99.99\%), nitrogen monoxide (NO, $4900 \mathrm{ppmV}$ ) and synthetic air were purchased from Beijing Huayuan Gas Chemical Industry Co. Ltd. (China). Dichloromethane (DCM, chromatographic grade) was from J. T. Baker Co.

\section{Results and discussion}

\subsection{Homogeneous reaction}

Anthracene vapor, generated by heating anthracene at (110 $\pm 2)^{\circ} \mathrm{C}$, was introduced into the chamber by flushing

Table 1 Anthracene and its reaction products detected and identified with GC/MS

\begin{tabular}{lll}
\hline$m / z$ & Assignment & Retention time (min) \\
\hline $178(179)$ & Anthracene (An) & 22.0 \\
194 & Anthrone (Ao) & 25.2 \\
208 & Anthraquinone (Aq) & 25.7 \\
$210^{*}(181)$ & $9,10-$ Dihydroxyanthracene & 23.5 \\
& (9,10-diOHAn) & \\
$223(193)$ & 9-Nitroanthracene (9-NA) & 28.7 \\
224 & 1-Hydroxyanthraquinone & 26.6 \\
& (1-OHAq) & \\
$226^{*}$ & 1,9,10-Trihydroxyanthracene & 30.4 \\
& (1,9,10-triOHAn) & \\
$240^{*}$ & 1,8-Dihydroxyanthraquinone & 27.0 \\
& $(1,8-$ diOHAq) & \\
\hline
\end{tabular}

*The $m / z$ with superscript represents other reaction products (isomers) may exist.
$\mathrm{N}_{2}$ at a constant flow rate of $0.5 \mathrm{~L} / \mathrm{min}$. The mass of anthracene vapor in the chamber was about $12.4 \mu \mathrm{g}$, which was estimated based on GC-FID measurement. The mass concentrations of aerosol in the chamber were monitored with SMPS before and after oxidants injection. There was a small amount of residual particles (about 5.78 $\times 10^{-2} \mu \mathrm{g} / \mathrm{m}^{3}$ ) when anthracene vapor was introduced into the chamber. After filling the reaction chamber with anthracene vapor $12.4 \mu \mathrm{g}$, the size distribution of aerosol in the chamber was monitored with SMPS for $105 \mathrm{~min}$. The range of mass concentrations of particles in the chamber was from $6.17 \times 10^{-2}$ to $9.22 \times 10^{-2} \mu \mathrm{g} / \mathrm{m}^{3}$, indicating that anthracene existed mainly in gas phase. After oxidants were introduced into the chamber, the mass concentrations of the particles increased rapidly and reached the maximum at about $20 \mathrm{~min}$ for $\mathrm{An}-\mathrm{O}_{3}-\mathrm{NO}$ and $50 \mathrm{~min}$ for $\mathrm{An}-\mathrm{O}_{3}$. Figure 1 shows the time-dependent mass concentrations of aerosol in the chamber after oxidants injection. This phenomenon indicates SOA formations from homogeneous reactions of gas-phase An with $\mathrm{O}_{3}$ and $\mathrm{O}_{3}$-NO. By fitting the mass concentrations of SOA as a function of time, the exponential growth rates of SOA obtained are 0.0013 for $\mathrm{An}-\mathrm{O}_{3}$ and 0.0044 for $\mathrm{An}-\mathrm{O}_{3}-\mathrm{NO}$ with the related coefficients $\left(R^{2}\right)$ of 0.94 and 0.84 , respectively. Since the concentrations of $\mathrm{O}_{3}$ does not change apparently, we think that the amount of oxidants are much more than that of An in the chamber and the reactions can be processed as pseudo first-order reactions. Additionally, the oxidations of An vapor are prior to the formation of SOA. Hence, the pseudo first-order rate constants of An vapor with $\mathrm{O}_{3}$ and $\mathrm{O}_{3}-\mathrm{NO}$ should be respectively larger than 0.0013 and 0.0044 which corresponds to the second order reactive rate constants $k_{\mathrm{O}_{3}}=9.5 \times 10^{-18}$ and $k_{\mathrm{O}_{3}+\mathrm{NO}}$ $=3.5 \times 10^{-17} \mathrm{~cm}^{3} /(\mathrm{mol} \cdot \mathrm{sec})$ in these experiments. The atmospheric lifetimes of gas phase An towards $\mathrm{O}_{3}\left(\tau_{\mathrm{O}_{3}}\right)$ and $\mathrm{O}_{3}-\mathrm{NO}\left(\tau_{\mathrm{O}_{3}+\mathrm{NO}}\right)$ are estimated to be 20.5 and $4.34 \mathrm{hr}$, calculated using the Eq. (1), when the concentrations of $\mathrm{O}_{3}$ and NO$x$ are about $1.43 \times 10^{12}$ and $4 \times 10^{11} \mathrm{~mol} / \mathrm{cm}^{3}$, respectively (Stroud et al., 2003).

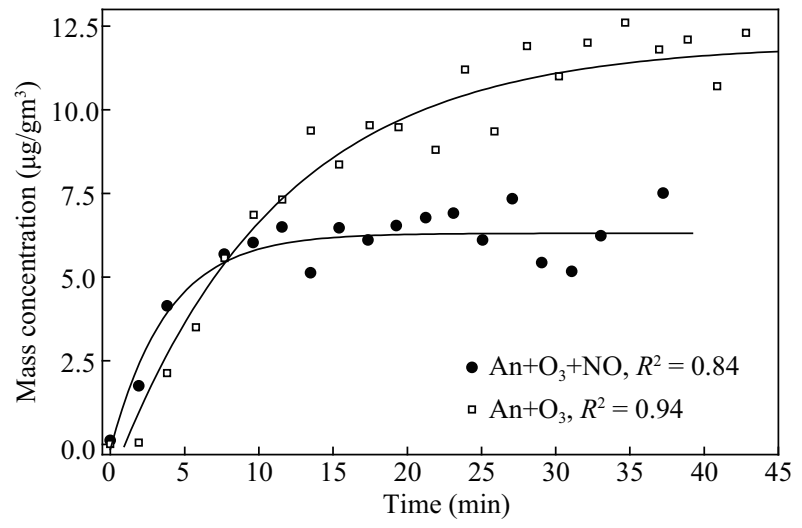

Fig. 1 Time-dependent mass concentrations of the secondary aerosol particles resulted from gas phase reaction of anthracene with $\mathrm{O}_{3}$ and $\mathrm{O}_{3}+\mathrm{NO}$. 


$$
\tau_{g}=\frac{1}{k_{g} \cdot[g]}
$$

where, $\tau_{g}, k_{g}$, and $[g]$ represent the atmospheric lifetimes, second order rate constants, and the concentrations of oxidants, respectively.

The size distribution changes from SOA formations as a function of time were monitored with SMPS. Figure 2 shows the typical time-dependant size distributions of SOA from experiments of $\mathrm{An}-\mathrm{O}_{3}$ and $\mathrm{An}-\mathrm{O}_{3}-\mathrm{NO}$, respectively. During both experiments, the overall shape of size distribution was polydispersed although the mean diameter of particles was shifted gradually to larger with reaction time. The difference is that single-peak size distribution is presented in $\mathrm{An}-\mathrm{O}_{3}$ experiment while double peaks in An$\mathrm{O}_{3}-\mathrm{NO}$ experiment. The reason may be that $\mathrm{NO}_{2}$ and $\mathrm{NO}_{3}$ radicals, formed from ozonation of $\mathrm{NO}$, are involved in reactions of SOA formation. The oxidation products with lower vapor pressure may be formed from $\mathrm{NO}_{2}$ and $\mathrm{NO}_{3}$ radicals-initiated reactions and thereby influenced the size distributions, though the concentrations of $\mathrm{NO}_{2}$ and $\mathrm{NO}_{3}$ radicals were much lower than that of $\mathrm{O}_{3}$.

Figure 3 shows the TOF mass spectra of SOA obtained by VUV-ATOFMS. In Fig. 3a, the mass peaks at $\mathrm{m} / \mathrm{z}$ 220 and 223 are contributed from the vapor of mechanical pump oil, which are hard to remove even with use of a liquid $\mathrm{N}_{2}$ trap in the detection chamber of ATOFMS. The mass peak at $m / z 178$ is resulted from the molecular ion of anthracene $\left(\mathrm{C}_{14} \mathrm{H}_{10}\right.$, molecular weight 178), indicating that An vapor can be adsorbed on the particles of SOA and thereby be detected by ATOFMS. The mass peak at $\mathrm{m} / \mathrm{z}$ 181 should correspond to the main product of the reaction. To assign this mass spectrum, the ozonation products were analyzed with GC/MS. However, no product was detected. The reason may be that the amount of products formed in the reaction was below the limit of detection. During

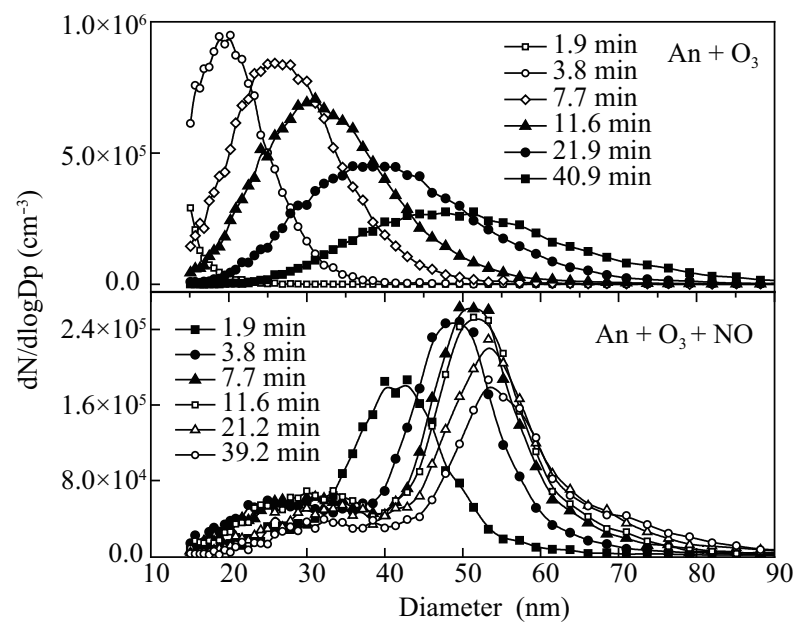

Fig. 2 Typical time-dependant size distributions of the secondary aerosol particles resulted from gas phase reaction of anthracene with $\mathrm{O}_{3}$ and $\mathrm{O}_{3}$ NO.

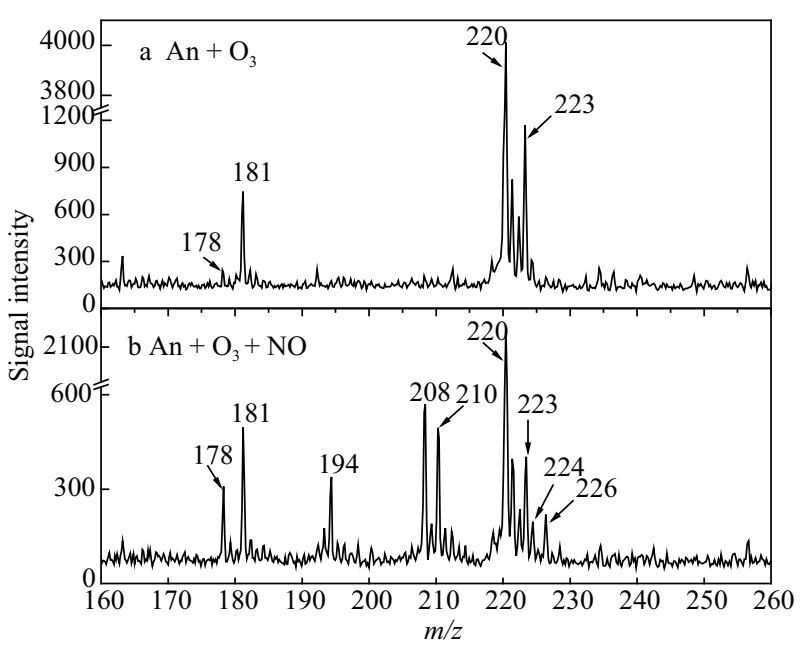

Fig. 3 TOF mass spectra of SOA formed form the reactions of gasphase anthracene with $\mathrm{O}_{3}$ (a) and $\mathrm{O}_{3}-\mathrm{NO}$ (b). (a) the mass spectrum was acquired $45 \mathrm{~min}$ after $\mathrm{O}_{3}$ injection and the acquisition time is $500 \mathrm{sec}$; (b) the mass spectrum was acquired $53 \mathrm{~min}$ after $\mathrm{O}_{3}-\mathrm{NO}$ injection and the acquisition time is $200 \mathrm{sec}$.

the $\mathrm{An}-\mathrm{O}_{3}-\mathrm{NO}$ experiment, the mass peaks at $m / z 181$, 194, 208, and 224 shown in Fig. 3b should be contributed from the oxidation products. In addition, no product was detected and identified by GC/MS due to the same reason as mentioned above.

\subsection{Heterogeneous reaction}

Compared to homogeneous reactions, heterogeneous reactions of particulate An present much stronger signals. Figure 4 shows the TOF mass spectra of An and their oxidation products. The mass peaks at $\mathrm{m} / z 178$ and 179 shown in Fig. 4a are contributed from $\mathrm{An}$ and ${ }^{13} \mathrm{C}$ An. Compared with the TOF mass spectrum shown in Fig. 4a, some new mass peaks appear at $m / z$ 181, 194, 208, 210, 224, and 226 shown in Fig. 4b. These peaks are contributed from the major heterogeneous reaction products of particle-phase An with $\mathrm{O}_{3}$. Based on GC/MS analyses, anthrone $\left(\mathrm{C}_{14} \mathrm{H}_{10} \mathrm{O}\right.$, molecular weight 194) and

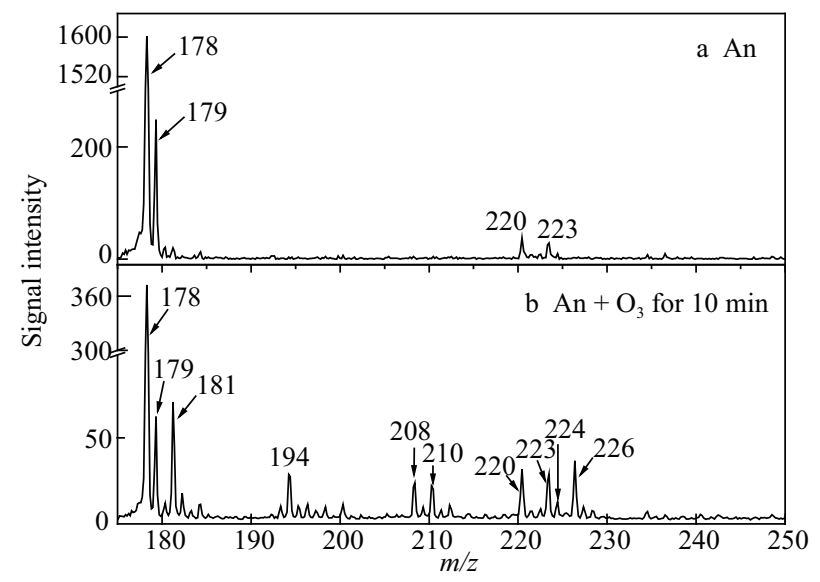

Fig. 4 TOF mass spectra of anthracene (a) and their ozonation products after reaction with $\mathrm{O}_{3}$ for $10 \mathrm{~min}$ (b). The acquisition time was $20 \mathrm{sec}$ for each mass spectrum. 
anthraquinone $\left(\mathrm{C}_{14} \mathrm{H}_{8} \mathrm{O}_{2}\right.$, molecular weight 208) corresponding to mass peaks at $\mathrm{m} / z, 194$ and 208 are identified as the two major products, and their retention time are 25.2 and $25.7 \mathrm{~min}$, respectively. The mass peak at $\mathrm{m} / \mathrm{z}$ 224 is tentatively assigned to the molecular ions of 1hydroxyanthraquinone $\left(\mathrm{C}_{14} \mathrm{H}_{8} \mathrm{O}_{3}\right.$, molecular weight 224$)$, identified by analyzing its EI mass spectrum (retention time, $26.6 \mathrm{~min}$ ) exhibiting strongly molecular ion at $\mathrm{m} / \mathrm{z}$ 224 and characteristic fragment ions at $m / z$ 181, 194, and 208. The mass peak at $m / z 210$ may be from 9,10dihydroxyanthracene $\left(\mathrm{C}_{14} \mathrm{H}_{10} \mathrm{O}_{2}\right.$, molecular weight 210) due to its EI mass spectrum (retention time, $26.6 \mathrm{~min}$ ) exhibiting molecular ion at $m / z 210$ and strong daughter ion at $m / z 181$. Therefore, the mass peak at $m / z 181$ may result from the daughter ion of $m / z 210$, similar with the results obtained during homogeneous reactions. Also, the mass peak at $\mathrm{m} / \mathrm{z} 226$ is tentatively assigned to be $1,9,10$ trihydroxyanthracene (see Table $\mathbf{1}, \mathrm{C}_{14} \mathrm{H}_{10} \mathrm{O}_{3}$, molecular weight 226) by matching its $\mathrm{m} / \mathrm{z}$ to molecular weight of possible ozonide of An.

Figure 5 shows the TOF mass spectra of An and their oxidation products from $\mathrm{An}-\mathrm{O}_{3}-\mathrm{NO}$ experiment. The mass peaks at $m / z 178$ (179), 194, 208, and 226 are respectively assigned to be anthracene, anthrone, anthraquinone, and 1,8-dihydroxyanthrone as discussed above. The mass peak at $m / z 223$, except from the vapor of mechanical pump oil, partly arises from the molecular ion of 9-nitroanthracene (9-NA), which was identified by GC/MS with the retention time at $28.7 \mathrm{~min}$. The mass peak at $\mathrm{m} / z 193$ is assigned to the daughter ion of 9-NA by losing a NO during the VUV photoionization. Unlike the reaction of $\mathrm{An}$ and $\mathrm{O}_{3}$, some new mass peaks located at $m / z$ 240, 257, 273, 286, 303 , and 319 arised and should be contributed from the reaction products from $\mathrm{An}-\mathrm{O}_{3}-\mathrm{NO}$ experiment. The mass peak of $\mathrm{m} / \mathrm{z}, 240$ is tentatively assigned to the molecular ion of 1,8-dihydroxyanthraquinone $\left(\mathrm{C}_{14} \mathrm{H}_{8} \mathrm{O}_{4}\right.$, molecular weight 240), possibly due to its EI mass spectrum (27.0 min, retention time) with the molecular ion peak at $\mathrm{m} / \mathrm{z}$ 240 and fragment ion peaks at $m / z 181,194,208$, and 224. No products corresponding to the mass peaks at $\mathrm{m} / \mathrm{z}$

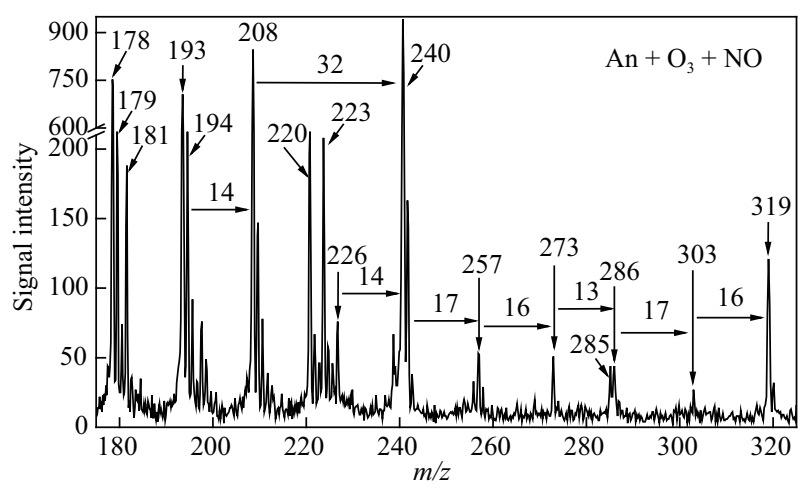

Fig. 5 TOF mass spectrum of the products resulted from the reaction of anthracene particles with $\mathrm{O}_{3}-\mathrm{NO}$ for $13 \mathrm{~min}$. The acquisition time was 20 sec.
257, 273, 286, 303, and 319 were detected by GC/MS in this work. The reason may be that these products are difficult to be gasified. The differences between some of these peaks are 16 and 17, which may indicate that these products formed were from adding a oxygen atom $(\mathrm{O})$, and hydroxyl $(\mathrm{OH})$, respectively. Our previous study also showed that 1,8-dihydroxyanthraquinone was the major product from the reaction of anthracene particles with $\mathrm{NO}_{3}$ radicals (Zhang et al., 2011), suggesting that much more oxygen-riched products are yielded when nitric oxidants involving such reactions.

\subsection{Reaction pathway}

It is known that the ozonation of PAHs starts initially from attacks of $\mathrm{O}_{3}$ on either $\mathrm{C}$ atom or $\mathrm{C}=\mathrm{C}$ double bond of the aromatic ring. The attack on $\mathrm{C}$ atom usually leads to substitution of $\mathrm{H}$ atoms followed by formation of phenol- or quinoid-type products, whereas the attack on $\mathrm{C}=\mathrm{C}$ double bond results in the ring cleavage followed by formyl- and carboxy-type products formation (Bailey, 1982; Perraudin et al., 2007; Wang et al., 2007; Yao et al., 1998a, 1998b). It has been reported that position 9(10)- of An is more susceptible to be attacked to produce anthrone and thereby further forming anthraquinone (Mmereki et al., 2004; Perraudin et al., 2007). In addition, $\mathrm{O}_{3}$ molecules can also simultaneously attack the positions 9 and 10 of anthracene by a cycloaddition and anthraquinone is finally produced in the secondary reaction (Calvert et al., 2000; Finlayson-Pitts and Pitts, 2000; Perraudin et al., 2007), which reaction mechanism may be similar to the reaction pathway of alkene ozonation. The concerted cycloaddition of ozone to the $9-10$ bond produces a vibrationally excited primary ozonide, which results in cleavage of one $\mathrm{O}-\mathrm{O}$ bond. Then, unstable intermediate is formed, which is also called Criegee intermediate (CI). However, the mechanism for subsequent fate of the $\mathrm{CI}$ is not very clear.

In the experiment of $\mathrm{An}-\mathrm{O}_{3}-\mathrm{NO}$, the production of 9nitroanthracene is relatively high, suggesting that $\mathrm{NO}_{3}$ radicals were formed and reacted with anthracene. The current postulated $\mathrm{NO}_{3}$ radical-initialed reaction mechanism of PAHs is that $\mathrm{NO}_{3}$ radicals attack the aromatic rings at the position of highest electron density in the PAH molecule (Arey et al., 1986; Atkinson et al., 1990; Gross and Bertram, 2008; Sasaki et al., 1997). According to the mechanism, the possible pathway of $\mathrm{An}-\mathrm{O}_{3}-\mathrm{NO}$ is suggested as follows: first, $\mathrm{NO}_{3}$ radicals can be expected to attack at position 9(10) of anthracene to form a $\mathrm{NO}_{3}-\mathrm{An}$ adduct; and then the adduct undergoes the reaction with $\mathrm{NO}_{2}$ at position 10 (para-position) of anthracene; finally, 9-nitroanthracene is formed via $\mathrm{H}$-atom abstraction and $\mathrm{HNO}_{3}$ elimination. Nevertheless, this mechanism can not explain why so much more oxygen-riched products are notably appeared in this experiment. In addition, our previous studies also showed that oxygenated products were formed during the reactions of $\mathrm{NO}_{3}$ radicals with anthracene, 
anthrone and 9-nitroanthracene. However, there is limited available data on heterogeneous reaction of anthracene with $\mathrm{NO}_{3}$ radicals, and the mechanisms for $\mathrm{NO}_{3}-\mathrm{PAH}$ surface reactions are still unclear. It is therefore difficult to explain the reason for formation of the oxygenated products. Thus, more works must be carried out to make clear the reaction mechanism of $\mathrm{PAH}$ with atmospheric oxidants.

\section{Conclusions}

Homogeneous and heterogeneous reactions of gas- and particle-phase anthracene with $\mathrm{O}_{3}$ and $\mathrm{O}_{3}-\mathrm{NO}$ in an aerosol reaction chamber were investigated. Reaction products were analyzed online with VUV-ATOFMS and identified offline by GC/MS. The formations of SOA resulted from oxidation of gas-phase anthracene by $\mathrm{O}_{3}$ and $\mathrm{O}_{3}-\mathrm{NO}$ were observed. The atmospheric lifetimes of gas-phase anthracene towards $\mathrm{O}_{3}$ and $\mathrm{O}_{3}-\mathrm{NO}$ are respectively less than 20.5 and $4.34 \mathrm{hr}$, which were derived from the formation rates of SOA. The products from the gas and particle phase anthracene were analyzed with VUV-ATOFMS. GC/MS analyses of reaction products of anthracene were also conducted for assigning the time-of-flight mass spectra of oxidation products from the homogeneous and heterogeneous reactions of anthracene. The main products were identified and detected. These results may help improve our understanding of the chemical transformation of anthracene in the atmosphere.

\section{Acknowledgments}

This work was supported by the funding for Creative Research Groups of China (No. 50921064), the China Postdoctoral Science Foundation Funded Project (No. 2011M500433) and the President Fund of GUCAS (No. Y25102GN00).

\section{References}

Arey J, Zielinska B, Atkinson R, Winer A M, Ramdahl T, Pitts J N, 1986. The formation of nitro-PAH from the gas-phase reactions of fluoranthene and pyrene with the $\mathrm{OH}$ radical in the presence of $\mathrm{NO}_{x}$. Atmospheric Environment, 20(12): 2339-2345.

Atkinson R, Arey J, 1994. Atmospheric chemistry of gas-phase polycyclic aromatic hydrocarbons: formation of atmospheric mutagens. Environmental Health Perspectives, 102(S4): $117-126$.

Atkinson R, Arey J, 2007. Mechanisms of the gas-phase reactions of aromatic hydrocarbons and $\mathrm{PAHs}$ with $\mathrm{OH}$ and $\mathrm{NO}_{3}$ radicals. Polycyclic Aromatic Compounds, 27(1): 15-40.

Atkinson R, Arey J, Zielinska B, Aschmann S M, 1990. Kinetics and nitro-products of the gas-phase $\mathrm{OH}$ and $\mathrm{NO}_{3}$ radicalintitated reactions of naphthalene- $D_{8}$, fluoranthene- $D_{10}$, and pyrene. International Journal of Chemical Kinetics, 22(9): 999-1014.
Atkinson R, Aschmann S M, 1988. Kinetics of the reactions of acenaphthene and acenaphthylene and structurally-related aromatic-compounds with $\mathrm{OH}$ and $\mathrm{NO}_{3}$ radicals, $\mathrm{N}_{2} \mathrm{O}_{5}$ and $\mathrm{O}_{3}$ at $296+/-2 \mathrm{~K}$. International Journal of Chemical Kinetics, 20(7): 513-539.

Bailey P S, 1982. Ozonation in Organic Chemistry Volumule II Nonolefenic Compounds. Academic Press, New York.

Calvert J G, Atkinson R, Becker K H, Kamens R M, Seinfeld J H, Wallington $\mathrm{T}$ J et al., 2000. The Mechanisms of Atmospheric Oxidation of Aromatic Hydrocarbons. Oxford University Press, New York.

Chuong B, Zhang J Y, Donahue N M, 2004. Cycloalkene ozonolysis: Collisionally mediated mechanistic branching. Journal of the American Chemical Society, 126(39): 12363-12373.

Durant J L, Busby W F, Lafleur A L, Penman B W, Crespi C L, 1996. Human cell mutagenicity of oxygenated, nitrated and unsubstituted polycyclic aromatic hydrocarbons associated with urban aerosols. Mutation Research-Genetic Toxicology, 371(3-4): 123-157.

Emmenegger C, Kalberer M, Samburova V, Zenobi R, 2005. High time resolution and size-segregated analysis of aerosolbound polycyclic aromatic hydrocarbons. Environmental Science and Technology, 39(11): 4213-4219.

Ervens B, Kreidenweis S M, 2007. SOA formation by biogenic and carbonyl compounds: Data evaluation and application. Environmental Science and Technology, 41(11): 39043910.

Finlayson-Pitts B J, Pitts J N Jr, 2000. Chemistry of the Upper and Lower Atmosphere: Theory, Experiments, and Applications. Academic Press, San Diego.

Gloaguen E, Mysak E R, Leone S R, Ahmed M, Wilson K $\mathrm{R}, 2006$. Investigating the chemical composition of mixed organic-inorganic particles by "soft" vacuum ultraviolet photoionization: The reaction of ozone with anthracene on sodium chloride particles. International Journal of Mass Spectrometry, 258(1-3): 74-85.

Gross S, Bertram A K, 2008. Reactive uptake of $\mathrm{NO}_{3}, \mathrm{~N}_{2} \mathrm{O}_{5}$, $\mathrm{NO}_{2}, \mathrm{HNO}_{3}$, and $\mathrm{O}_{3}$ on three types of polycyclic aromatic hydrocarbon surfaces. Journal of Physical Chemistry A, 112(14): 3104-3113.

Helmig D, Harger W P, 1994. OH radical-initiated gas-phase reaction products of phenanthrene. Science of the Total Environment, 148(1): 11-21.

Herner H A, Trosko J E, Masten S J, 2001. The epigenetic toxicity of pyrene and related ozonation byproducts containing an aldehyde functional group. Environmental Science and Technology, 35(17): 3576-3583.

Kahan T F, Kwamena N O A, Donaldson D J, 2006. Heterogeneous ozonation kinetics of polycyclic aromatic hydrocarbons on organic films. Atmospheric Environment, 40(19): 3448-3459.

Kanakidou M, Seinfeld J H, Pandis S N, Barnes I, Dentener F J, Facchini M C et al., 2005. Organic aerosol and global climate modelling: a review. Atmospheric Chemistry and Physics, 5(4): 1053-1123.

Kou J H, Zhang $\mathrm{H}$ T, Yuan Y P, Li Z S, Wang Y, Yu T et al., 2008. Efficient photodegradation of phenanthrene under visible light irradiation via photosensitized electron transfer. Journal of Physical Chemistry C, 112(11): 4291- 
4296.

Kwamena N O A, Earp M E, Young C J, Abbatt J P D, 2006. Kinetic and product yield study of the heterogeneous gas-surface reaction of anthracene and ozone. Journal of Physical Chemistry A, 110(10): 3638-3646.

Kwamena N O A, Staikova M G, Donaldson D J, George I J, Abbatt J P D, 2007. Role of the aerosol substrate in 'the heterogeneous ozonation reactions of surfacebound PAHs. Journal of Physical Chemistry A, 111(43): 11050-11058.

Ma J Z, Liu Y C, He H, 2011. Heterogeneous reactions between $\mathrm{NO}_{2}$ and anthracene adsorbed on $\mathrm{SiO}_{2}$ and $\mathrm{MgO}$. Atmospheric Environment, 45(4): 917-924.

Ma J, Liu Y C, He H, 2010. Degradation kinetics of anthracene by ozone on mineral oxides. Atmospheric Environment, 44(35): 4446-4453.

Miet K, Budzinski H, Villenave E, 2009a. Heterogeneous reactions of $\mathrm{OH}$ radicals with particulate-pyrene and 1nitropyrene of atmospheric interest. Polycyclic Aromatic Compounds, 29(5): 267-281.

Miet K, Le Menach K, Flaud P M, Budzinski H, Villenave E, 2009b. Heterogeneous reactions of ozone with pyrene, 1-hydroxypyrene and 1-nitropyrene adsorbed on particles. Atmospheric Environment, 43(24): 3699-3707.

Miet K, Le Menach K, Flaud P M, Budzinski H, Villenave E, 2009c. Heterogeneous reactivity of pyrene and 1-nitropyrene with $\mathrm{NO}_{2}$ : Kinetics, product yields and mechanism. Atmospheric Environment, 43(4): 837-843.

Mmereki B T, Donaldson D J, 2003. Direct observation of the kinetics of an atmospherically important reaction at the airaqueous interface. The Journal of Physical Chemistry A, 107(50): 11038-11042.

Mmereki B T, Donaldson D J, Gilman J B, Eliason T L, Vaida $\mathrm{V}, 2004$. Kinetics and products of the reaction of gasphase ozone with anthracene adsorbed at the air-aqueous interface. Atmospheric Environment, 38(36): 6091-6103.

Nájera J J, Wamsley R, Last D J, Leather K E, Percival C J, Horn A B, 2011. Heterogeneous oxidation reaction of gasphase ozone with anthracene in thin films and on aerosols by infrared spectroscopic methods. International Journal of Chemical Kinetics, 43(12): 694-707.

Nikolaou K, Masclet P, Mouvier G, 1984. Sources and chemical reactivity of polynuclear aromatic hydrocarbons in the atmosphere-A critical review. Science of the Total Environment, 32(2): 103-132.

Perraudin E, Budzinski H, Villenave E, 2007a. Identification and quantification of ozonation products of anthracene and phenanthrene adsorbed on silica particles. Atmospheric Environment, 41(28): 6005-6017.

Perraudin E, Budzinski H, Villenave E, 2007b. Kinetic study of the reactions of ozone with polycyclic aromatic hydrocarbons adsorbed on atmospheric model particles. Journal of Atmospheric Chemistry, 56(1): 57-82.

Pitts J N, van Cauwenberghe K A, Grosjean D, Schmid J P, Fitz D R, Belser W L et al., 1978. Atmospheric reactions of polycyclic aromatic-hydrocarbons: facile formation of mutagenic nitro derivatives. Science, 202(4367): 515-519.
Pöschl U, Letzel T, Schauer C, Niessner R, 2001. Interaction of ozone and water vapor with spark discharge soot aerosol particles coated with benzo[a]pyrene: $\mathrm{O}_{3}$ and $\mathrm{H}_{2} \mathrm{O}$ adsorption, benzo[a]pyrene degradation, and atmospheric implications. Journal of Physical Chemistry A, 105(16): 4029-4041.

Raja S, Valsaraj K T, 2006. On the reactive uptake of gaseous PAH molecules by micron-sized atmospheric water droplets. Atmospheric Research, 81(4): 277-292.

Sasaki J, Aschmann S M, Kwok E S C, Atkinson R, Arey $\mathrm{J}, 1997$. Products of the gas-phase $\mathrm{OH}$ and $\mathrm{NO}_{3}$ radicalinitiated reactions of naphthalene. Environmental Science and Technology, 31(11): 3173-3179.

Shu J N, Gao S K, Li Y, 2008. A VUV photoionization aerosol time-of-flight mass spectrometer with a RF-powered VUV lamp for laboratory-based organic aerosol measurements. Aerosol Science and Technology, 42(2): 110-113.

Sitaras I E, Bakeas E B, Siskos P A, 2004. Gas/particle partitioning of seven volatile polycyclic aromatic hydrocarbons in a heavy traffic urban area. Science of the Total Environment, 327(1-3): 249-264.

Stroud C, Madronich S, Atlas E, Ridley B, Flocke F, Weinheimer A et al., 2003. Photochemistry in the arctic free troposphere: NO $x$ budget and the role of odd nitrogen reservoir recycling. Atmospheric Environment, 37(24): 3351-3364.

Umbuzeiro G A, Franco A, Martins M H, Kummrow F, Carvalho $\mathrm{L}$, Schmeiser $\mathrm{H} \mathrm{H}$ et al., 2008. Mutagenicity and DNA adduct formation of PAH, nitro-PAH, and oxy-PAH fractions of atmospheric particulate matter from Sao Paulo, Brazil. Mutation Research-Genetic Toxicology and Environmental Mutagenesis, 652(1): 72-80.

Vasilakos C, Levi N, Maggos T, Hatzianestis J, Michopoulos J, Helmis C, 2007. Gas-particle concentration and characterization of sources of PAHs in the atmosphere of a suburban area in Athens, Greece. Journal of Hazardous Materials, 140(1-2): 45-51.

Vione D, Barra S, De Gennaro G, De Rienzo M, Gilardoni S, Perrone M G et al., 2004. Polycyclic aromatic hydrocarbons in the atmosphere: monitoring, sources, sinks and fate. II: Sinks and fate. Annali di Chimica, 94(4): 257-268.

Wang L, Atkinson R, Arey J, 2007. Formation of 9,10phenanthrenequinone by atmospheric gas-phase reactions of phenanthrene. Atmospheric Environment, 41(10): 2025 2035.

Yao J J, Huang Z H, Masten S J, 1998a. The ozonation of benz[a]anthracene: Pathway and product identification. Water Research, 32(11): 3235-3244.

Yao J J, Huang Z H, Masten S J, 1998b. The ozonation of pyrene: Pathway and product identification. Water Research, 32(10): 3001-3012.

Zhang Y, Yang B, Gan J, Liu C, Shu X, Shu J, 2011. Nitration of particle-associated PAHs and their derivatives (nitro-, oxy-, and hydroxy-PAHs) with $\mathrm{NO}_{3}$ radicals. Atmospheric Environment, 45(15): 2515-2521.

Zhang Y, Yang B, Meng J W, Gao S K, Dong X Y, Shu J $\mathrm{H}, 2010$. Homogeneous and heterogeneous reactions of phenanthrene with ozone. Atmospheric Environment, 44(5): 697-702. 